\title{
Involving technogenic mineral resources in the production of "glass-steel" compositions
}

\author{
Vera Makarova ${ }^{1 . *}$ \\ ${ }^{1}$ Vladivostok state university of economics and service, 41 Gogolya St., Vladivostok, 690014, Russia
}

\begin{abstract}
The purpose of this study is to ensure the sustainable development of society by reducing the use of natural resources. Waste from the mining and metallurgical sector is a valuable raw material for the making of glass-steel compositions. The obtained results show that the involvement of man-made waste positively affects the physico-mechanical and operational properties of enamel slurries. The involvement of mining and metallurgical sector waste in the technological cycle of obtaining glass-steel compositions will allow expanding the mineral base for the production of protective coatings while simultaneously ensuring the requirements of environmental safety and protection.
\end{abstract}

\section{Introduction}

One of the priorities of human development is sustainable development. This is not just about establishing some external borders in development, for example, limiting the amount of natural resources used, but also about such an important indicator as the compensatory capacity of the biosphere [1], because development in harmony with the environment can contribute to meeting a number of pressing needs of people [2].

From the ecological point of view, sustainable development should be characterized by the development of biosphere-compatible technologies, with a general decrease in the anthropogenic press on the biosphere. At the same time, newly developed technologies can be aimed both at minimizing the quantity of newly formed wastes or their absence, and for processing earlier accumulated wastes.

$100 \%$ use of the natural raw materials is not achieved in the manufacture of the end product, because the existing technologies are imperfect, due to the structural features of any given apparatuses, plants, or another processing equipment [3].

This results in creation of huge amount and diversified chemical composition of production-induced wastes, which, in the context of the present terminology, are commonly referred to as disperse systems of technogenic origin.

The term "production wastes" covers not only the wastes generated as a result of mechanical and physical-chemical processing of raw stock and materials, but also the wastes generated during mining and enrichment of minerals [3].

The great chemist, D.I. Mendeleev, expressed an idea that «wastes are also raw materials, but not used in the given production» $[3,4]$.

\footnotetext{
*Corresponding author: boyikova@mail.ru
} 
In our opinion, by further developing the ideas of D.I. Mendeleev, we treat the production-induced materials as mineral and energy raw materials capable of providing new bonds, disperse structures, but with other physical, mechanical and chemical characteristics.

Raw materials are very important for the sustainable functioning of modern societies. Accessibility and affordability of the mineral raw materials are of crucial significance for healthy functioning of the economy.

A growing demand for raw materials increases concern regarding the quantity of mineral resources and especially the availability of metals. Besides, many metals, metalloids or rare earth elements, which have not been utilized in the past, are now being used for manufacture of value-added products, especially in the sphere of the new and green technologies. Many of them are byproducts of manufacturing base metals, and their reserves are very limited [5$6]$.

Mining industry has been inflicting damage on the environment for thousands of years. Thus, the scientists in Spain are conducting comparison of research regarding the impact of the ancient mining operations, in the watershed rock, and the modern mining production. This will allow to forecast a long-term behavior of the modern sediments in this area contaminated with metals [7].

An enormous quantity of the so-called overburden rock is created in the course of mining the mineral deposits. The authors of the scientific paper [8] offer to return such rocks to the place of their extraction after finishing exploitation of a deposit. However, it is not always expedient, since they might contain a considerable number of elements, so it is not necessary to perform extraction again.

Accumulation of mining wastes is typical for various countries [9-11]. The main obstacles for efficient use of wastes have been identified and broken down by the authors [5] into several constituent parts. One of such constituents is efficient use of the byproducts of such production.

Mining and metallurgy sector wastes are given attention for the purpose of assessing their influence on the components of the environment, as well as for a feasible recovery from them of valuable metals. In France, a recently started project is aimed at identifying on a nationwide scale interesting mining wastes from the old deposits and assessing the metal recovery potential of these wastes. On a first step, it focuses on previous sites that need to be rehabilitated [5].

Thus, the author [12] states that the wastes from manufacturing electrolytic manganese dioxide can be used in the production of enamels and in this way to obtain decorative coatings with stable processing parameters.

In fact, the recycling of wastes generated by one kind of production in another kind of manufacture, will allow to speak about the desire to reduce the amount of waste generation, taking into consideration the fact that in the opinion of the authors [13-14], it would be reasonable to speak only about low-waste production, which is not treated as an «intermediate step» to achieving a «practically waste-free production», but as a final goal.

The disperse structures, as is known from the papers of A. A. Appen, F.D. Ovcharenko, N.N. Kruglitsky [15-17], cover the compounds, synthesized under the conditions not only of the nature-and-raw materials formation of certain minerals, but also in the real technologies in processing of the mineral raw materials in recovery of the metals ( $\mathrm{Ti}, \mathrm{Al}, \mathrm{Zr}, \mathrm{Fe}, \mathrm{Mn}$ ), and also the oxide compounds in the form of titanium pigments; ceramic and glass-enamel dampers.

According to the modern physical and chemical views, the glass-like state is an amorphous non-equilibrium condition, occurring as a result of liquid overcooling or increasing the impact of pressure on it. The glassy state, being metastable, differs from the crystalline state by the surplus amount of internal energy. The spatial distribution of the substance particles in the glassy state is disordered. 
The specific feature of the glass structure is the presence of the short-range order only, which, in case of oxide glasses (they include the majority of glass frits) characterizes the location of the oxygen anions, halogens relative to the cations, for example, in the groupings $\left[\mathrm{SiO}_{4}\right]^{4-}$ or $\left[\mathrm{SiO}_{3}\right]^{3-}[18]$.

The specific properties of glasses include the lack of the definite temperature of hardening or melting. When assessing the tendency of the materials to glass formation, it is a common practice to take into account crystalline and chemical notions on the composition and structure of glasses and atomic characteristics of cations and anions [18].

The glasses intended for protection of the steel substrate, contain a great number of components that include glass formers $\left(\mathrm{B}^{3+}, \mathrm{Si}^{4+}, \mathrm{Ge}^{4+}\right)$, modifiers $\left(\mathrm{Li}^{+}, \mathrm{Na}^{+}, \mathrm{K}^{+}, \mathrm{Ca}^{2+}, \mathrm{Mg}^{2+}\right.$, $\left.\mathrm{Fe}^{2+}\right)$ and glass former-modifiers $\left(\mathrm{Al}^{3+}, \mathrm{Ti}^{4+}, \mathrm{Zr}^{4+}\right)$. Numerous industrial compositions of glasses for protection of steel are synthesized on the basis of glass formers, modifiers and create complex systems of alkali alumina-borosilicate nature. The glass-like structures have their specific properties due to the presence in their composition of several anions: oxygen, fluorine and chlorine [19].

Due to the combined presence of glass formers, modifiers and several anions, the glasslike materials have a number of physical and chemical properties: crystallization capacity, viscosity, surface tension, wetting ability, corrosive ability of molten mass, which determines the intensity of the interaction processes in the systems «steel - glass - coating».

According to A. A. Appen [10, 15], the molten glass fixation on the steel substrate is electrochemical in nature, where the overall reaction of interaction between the molten glass and steel is divided into two phases: oxidation-recovery and local differentiation of the oxidizing (anode areas) and restorative (cathodic) processes.

As this takes place, steel is subjected to oxidation, while the components of the molten glass are being recovered. The typical oxidizers relative to steel and molten glass are the compounds of groups VI and VII in the periodic table of elements $(\mathrm{O}, \mathrm{F}, \mathrm{Cl}, \mathrm{S})$; cations of $d$ elements ( $\mathrm{Ti}, \mathrm{Fe}^{3+}, \mathrm{Cu}^{2+}, \mathrm{Zr}^{4+}$ etc.), as well as cations $\mathrm{Me}^{+}, \mathrm{Me}^{2+}$.

\section{Practical Relevance, Results of Experimental Research}

The subject of the study was the waste of the Volnogorsk Mining and Metallurgical Plant. This waste was used in the production of "glass-steel" compositions as a component of enamel slurry.

Due to microalloying of glass-forming oxides, the production of protective compositions is very promising for the compounds of the s1-, p1, -d-elements ( $\mathrm{Ti}, \mathrm{Al}, \mathrm{Zr}, \mathrm{Fe}$, etc.) contained in products and materials of technogenic origin. Involving production waste in a new technological cycle will reduce its number, which will positively affect the quality of the environment.

The enamel slurry, which includes the frit of the $\mathrm{Na}_{2} \mathrm{O}-\mathrm{CaF}_{2}-\mathrm{Al}_{2} \mathrm{O}_{3}-\mathrm{B}_{2} \mathrm{O}_{3}-\mathrm{TiO}_{2}-\mathrm{SiO}_{2}$ system, clay, quartz sand, borax, water, additionally contains an additive of man-caused waste from the ore-dressing plant at the following ratio of components, pts. wt.: frits 100 ; clay 3-5; sand quartz 5-20; borax 0.1-0.4; water 40-50; man-caused waste of the ore mining and processing plant 3-15.

For the preparation of enamel slurries, along with conventional materials, man-caused waste of the Volnogorsk Mining and Metallurgical Plant was used, having the following chemical composition, mass \%: $\mathrm{SiO}_{2}-44.2 ; \mathrm{Al}_{2} \mathrm{O}_{3}-34.8 ; \mathrm{TiO}_{2}-8.4 ; \mathrm{Zr}_{2} \mathrm{O}_{2}-4.6 ; \mathrm{Fe}_{2} \mathrm{O}_{3}-$ 6.0 .

As a frit, the chemical composition of ground silicate enamel was used in the system $\mathrm{Na}_{2} \mathrm{O}-\mathrm{CaF}_{2}-\mathrm{Al}_{2} \mathrm{O}_{3}-\mathrm{B}_{2} \mathrm{O}_{3}-\mathrm{TiO}_{2}-\mathrm{SiO}_{2}$, which contains: $\mathrm{SiO}_{2}-41.0 ; \mathrm{B}_{2} \mathrm{O}_{3}-0.7 ; \mathrm{Na}_{2} \mathrm{O}-22.1$; $\mathrm{CaF}_{2}-7.4 ; \mathrm{Al}_{2} \mathrm{O}_{3}-7.0 ; \mathrm{CoO}-0.3 ; \mathrm{TiO}_{2}-0.5 ; \mathrm{NiO}-1.0$. 
For the preparation of enamel slurries, the components are ground in a ball mill to a fineness of grinding (21-26) $10^{-1} \mathrm{~mm}$.

The resulting slurry is applied to the products by spraying, dried and fired. Coating temperature $780-880^{\circ} \mathrm{C}$, firing interval $90-140^{\circ} \mathrm{C}$.

Table 1 shows the compositions of the proposed slurry.

Table 1. Composition of slurries.

\begin{tabular}{|c|c|c|c|c|}
\hline \multirow{2}{*}{ Components } & \multicolumn{4}{|c|}{ Composition of components, pts. wt. } \\
\cline { 2 - 5 } & 1 & 2 & 3 & Control sample \\
\hline Frit & 100 & 100 & 100 & 100 \\
\hline Quartz sand & 5 & 15 & 20 & 10 \\
\hline Clay & 3 & 4 & 5 & 6 \\
\hline Borax & 0.1 & 0.4 & 0.3 & 0.5 \\
\hline Technogenic waste & 3 & 7 & 15 & - \\
\hline Water & 40 & 45 & 50 & 45 \\
\hline
\end{tabular}

The characteristics of the physical-mechanical and operational properties of the proposed slurries in comparison with the control sample, such as: abrasion (Figure 1), strength of adhesion to steel: impact and bending is shown in Figures 2 and 3, where 1,2,3 - raw materials with different waste content, 4 - control sample (without waste).

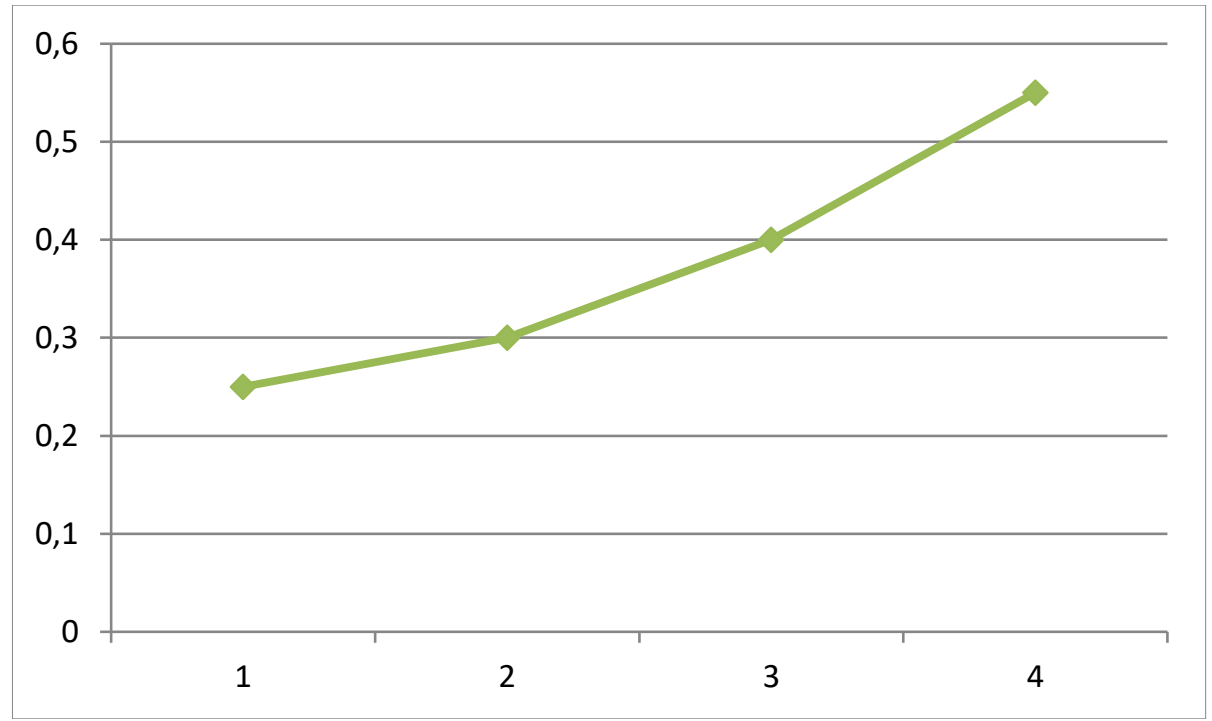

Fig. 1. Abrasion, g/dm² 


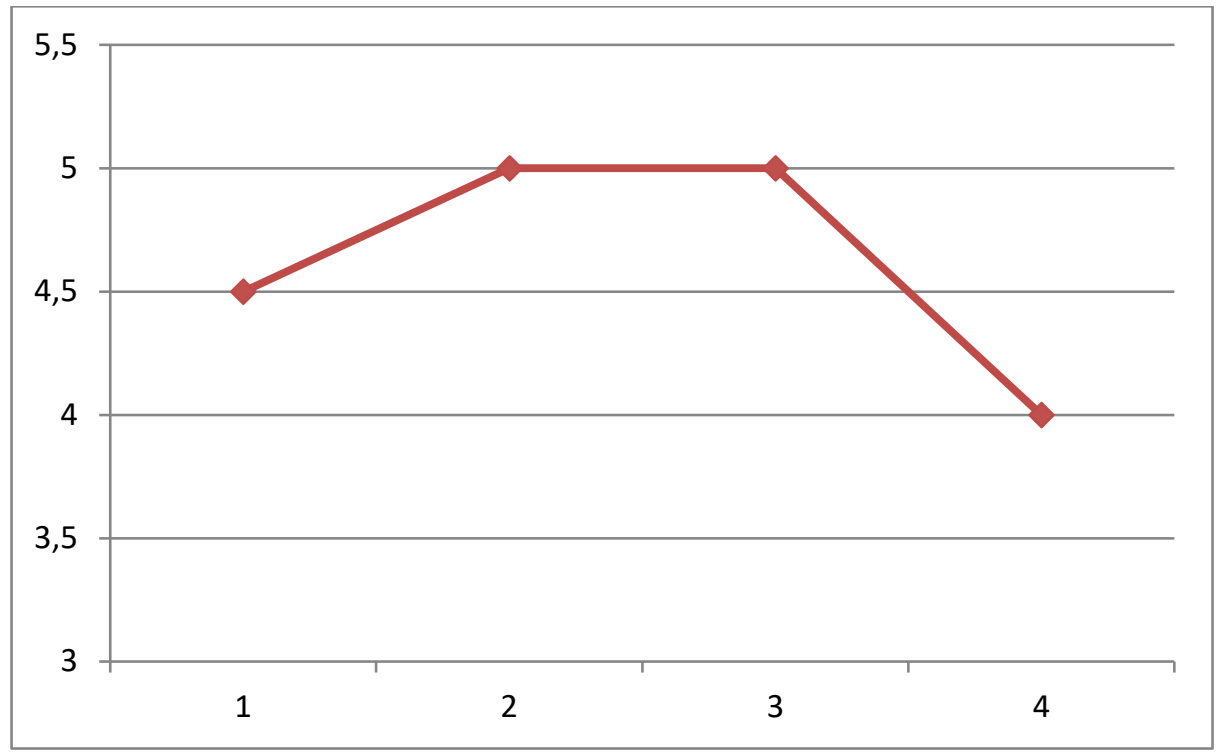

Fig. 2. Impact strength, kgm.

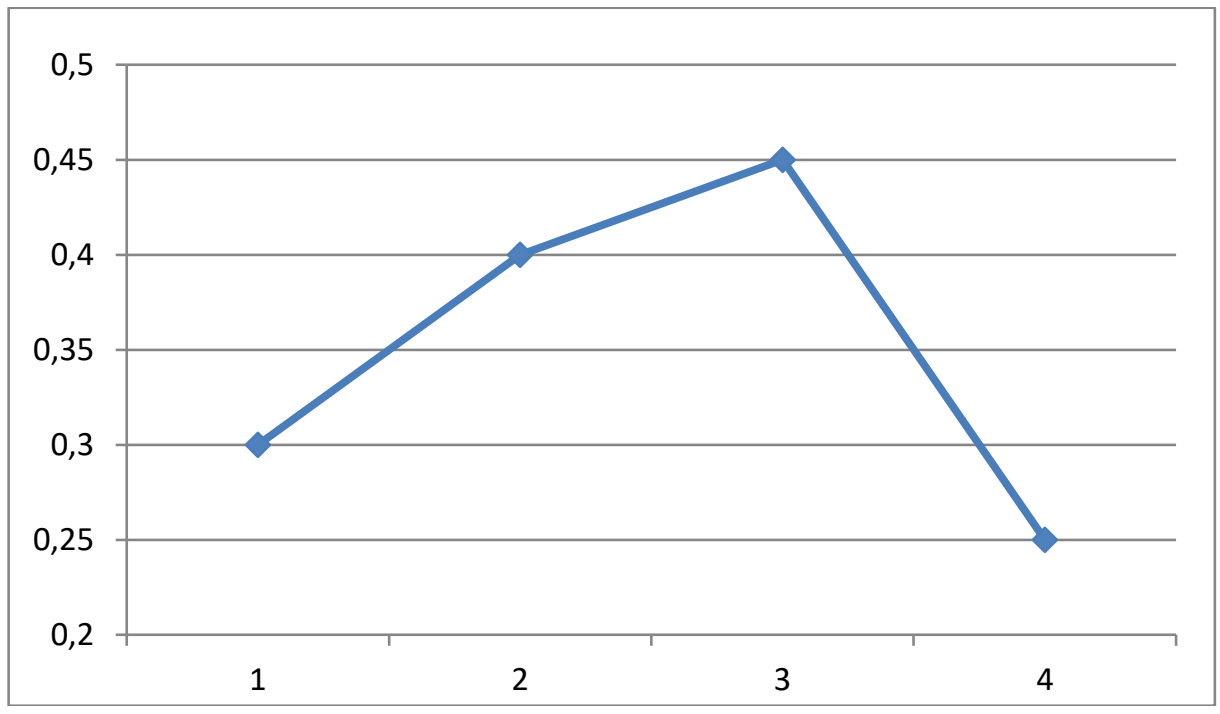

Fig. 3. Bending strength, points.

The obtained data show that the involvement of man-caused waste positively affects the physical-mechanical and operational properties of the slurries.

These principles are the basis of the proposed technology (Fig. 4), which ensures the making of products from sheet metal, protected by an anti-corrosion glassy coating.

In a generalized form, the results of work represent the principles of the directed regulated phase composition and the structure of the glass-like materials with a set of prespecified properties:

1. The principle of nanostructuring by means of disappearance of the original components and compounds, new formation of phases in glasses, which undergo nano-scale level at the temperatures of the compositions' kilning.

2. The principle of increasing the corrosive activity by means of forming solid solutions. 
3. The principle of the maximum adaptation to the external heat loads by means of selforganization of the phase composition and creation of the glass-like material structure.

4. The principle of influence by the new formation on the properties of the final glass-like combination, increase of the number of phases in the compositions «glass-steel».

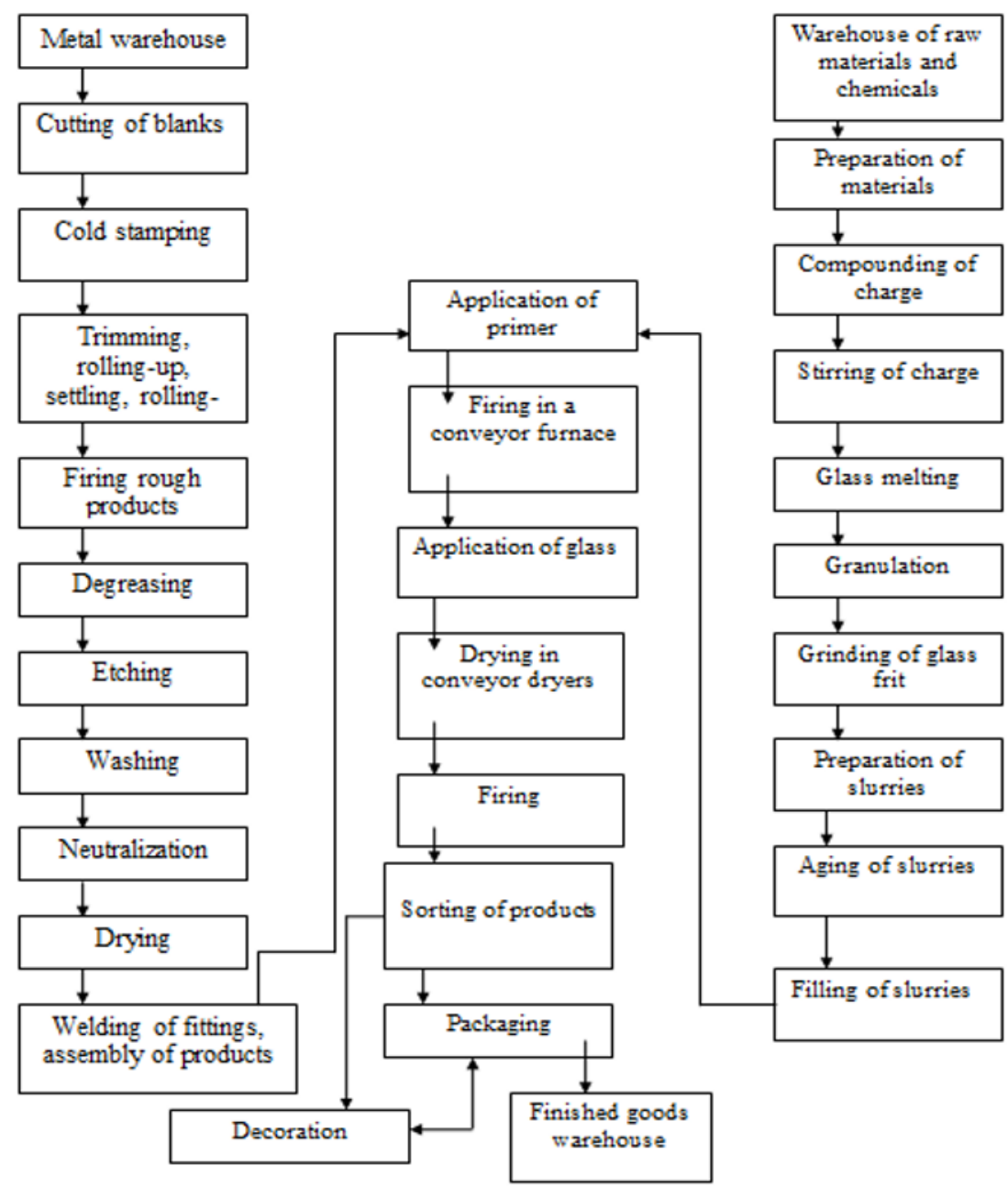

Fig. 4. Scheme for the making of steel products protected by glass under the proposed technology.

\section{Conclusions}

The ultimate goal of the work is to expand the mineral base for the making of steel products with a protective coating based on the physico-chemical principle "likes attract"; meantime, forming structural groups that provide improved mechanical and physical indicators. The practical result of research in the system "natural raw materials - dispersed products of technogenic origin" is an enamel slip synthesized.

Thus, on the basis of the physical and chemical interrelation of the disperse structures and materials of technogenic origin, the scientific foundations for obtaining protective coatings were created providing for the use of compositions «glass-steel substrate», based on the concept, which generalizes the regular patterns and peculiarities of the reaction progress with the processes of the directed gas generation and formation of the structure, ensuring the 
desired physical, mechanical and chemical properties of the product within the system «functional glass-steel substrate». The involvement of technogenic mineral resources in the production cycle increases the level of environmental safety in the region and improves the state of the environment. This paper has proved not only the practical relevance of using the industrial wastes, but also provided the scientific rationale for the competent usage of wastes containing the compounds of diagonal analogs and vertical homologues, elements of delectronic family. Ultimately, thanks to the completed work, the problem of national importance is solved, because the raw material base for production of the protective coatings is expanded with the simultaneous fulfillment of the environmental safety requirements and protection of the natural environment.

Thus, one of the tasks of the work has been solved, namely, scientifically-qualified management of material/resource saving by developing a physico-chemical approach based on the principle of "technology-ecology-economy".

\section{References}

1. V.A. Cherdantsev, B.V. Robinson, Vestnik NSUEM J. E 2, 14-24 (2009)

2. H.N. Gizatullin, V.A. Troitskiy, Social sciences and contemporary world J. 5, 124-130 (1998)

3. B.B. Bobovich, Processing of industrial wastes (Intermet Engineering, Moscow, 1999)

4. D.I. Mendeleev, Biosphere and noosphere (Nauka, Moscow, 1989)

5. G. Bellenfant, A.G. Guezennec, F. Bodenan, et.al. Mine Closure 9, 571-582 (2013)

6. B.G. Lottermoser, J. Elements 7, 405-410 (2014)

7. M. Leblanc, J.A. Morales, J. Borrego, et.al. J. Economic Geology 95, 655-662 (2000)

8. K. Abdelhadi, O. Latifa, B. Khadija, et.al. International J. of Mining Science and Technology 26(3), 511-516 (2011)

9. M.A. Nevskaya, S.V. Fedoseev, O.A. Marinina, Int.J. of Applied Engineering Research E 11(16), 9018-9025 (2016)

10. Yu.L. Savin, A.P. Prihodko, L.S. Savin, et.al. Bulletin of Dnipropetrovsk National University of Railway Transport 31, 193-197 (2010)

11. Z.M. Bobrova, O.Yu. Ilina, A.V. Khokhryakov, E.M. Tseitlin, News of the Ural State Mining University 4(40), 16-26 (2015)

12. I.G. Berdzenishvili, Proc.8-th Int. Conf. WasteECo-2011 (Kharkiv, 2015)

13. V.E. Lotosh, Fundamental principles of nature management (Poligrafist, Ekaterinburg, 2007)

14. V.N. Korotaev, N.N. Slyusar, Ya.A. Zhilinskaya, G.V. Ilinyih, T.G. Filkin, Management of industrial wastes (Perm. polytechnical. University, Perm, 2016)

15. A.A. Appen, Chemistry of Glass (Chemistry, Leningrad, 1974)

16. N.N. Kruglitskiy, Fundamentals of physico-chemical mechanics. Part 2 (Vischa shkola, Kiev, 1976)

17. F.D. Ovcharenko, N.N. Kruglitskiy, S. P. Nichiporenko, et.al. Research in the field of physico-chemical mechanics dispersion of clay minerals (Nauk.dumka, Kiev, 1965)

18. A. Pettsold, Enamel (Metallurgizdat, Moscow, 1958)

19. P.A. Rebinder, Physicochemical mechanics - a new field of science (Znanie, Moscow, 1958)

20. V.N. Makarova, J. ASR: Economics and Management 2(23), 215-218 (2018) 